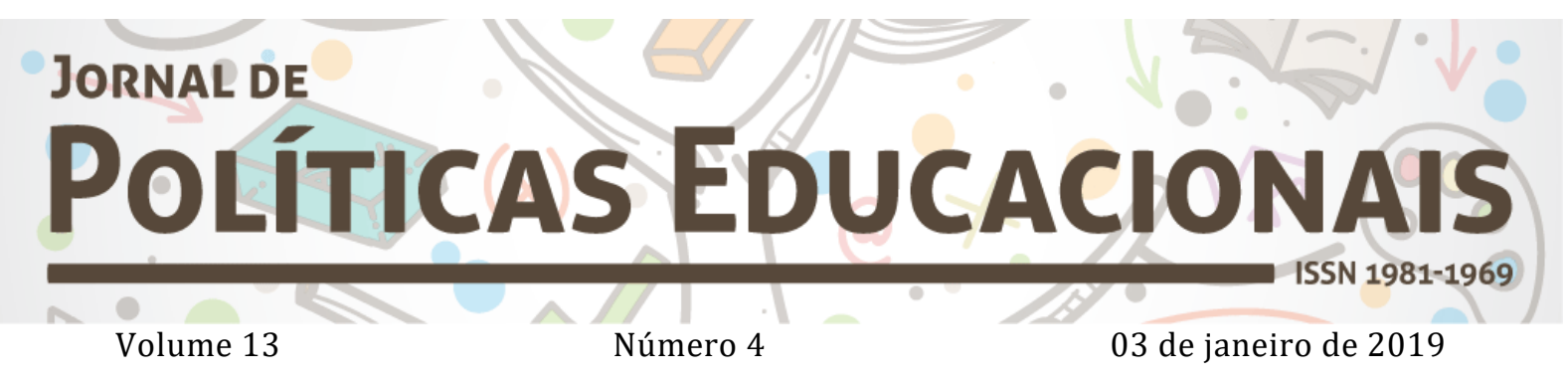

\title{
Aplicação dos recursos do PROAP na UFPB: um estudo de caso
}

\author{
Application of PROAP resources at UFPB: a study case
}

\section{Aplicación de los recursos del PROAP en la UFPB: un estudio de caso}

\author{
Débora Lopes do Rego' \\ Luir de Sousa Junior ${ }^{2}$
}

Citação: REGO, D. L.; SOUSA JR., L. Aplicação dos recursos do PROAP na UFPB: um estudo de caso. Jornal de Políticas Educacionais. V. 13, n. 4. Janeiro de 2019.

http://10.5380/jpe.v13i0.62468

\section{Resumo}

O presente trabalho tem por objetivo central analisar a gestão dos recursos do PROAP (Programa de Apoio à Pós-Graduação) no âmbito da UFPB no ano de 2014. Grandes desafios e metas foram estabelecidos para a Pós-Graduação brasileira pelo Plano Nacional de Pós-Graduação - PNPG (2011-2020) e há relativo consenso quanto à necessidade de ampliar o investimento. No entanto, os recursos do PROAP encaminhados para UFPB não foram utilizados em sua totalidade no ano de 2014. Questiona-se, portanto, o modo como foi efetivada a gestão desses recursos pelas Unidades Gestoras responsáveis pela aplicação dos recursos. Embora sejam considerados de pequena monta em relação ao orçamento total da UFPB, são imprescindíveis para o pleno desenvolvimento da Pós-Graduação. Daí a relevância de se estudar a gestão de tais recursos. Com base em dados obtidos junto ao Tesouro Gerencial, CAPES e UFPB, constatou-se que a mudança gerencial dos recursos PROAP em meio ao exercício financeiro de 2014, sem qualquer estudo ou planejamento, resultou na expressiva devolução de tais recursos.

Palavras-Chave: Pós-Graduação; Gestão; Políticas de Financiamento; Planejamento; PROAP.

\begin{abstract}
The main objective of this work is to analyze the PROAP (Postgraduate Support Program) management resources at UFPB in 2014. Major challenges and goals were established for the Brazilian Postgraduation by the National Postgraduate Plan - PNPG (2011-2020) and there is a relative consensus about the need to expand the investment. However, the resources of PROAP sent to UFPB were not used in their entirety in the year 2014. Therefore, it is questioned how the management of these resources was managed by the Management Units responsible for the resource's application. Although they are considered small in relation to the total budget of the UFPB, they are essential for the full development of Postgraduate Studies. Hence the relevance of studying the management of such resources. Based on primary data obtained from the Tesouro Gerencial, CAPES and UFPB, it was found that the managerial change of PROAP

\footnotetext{
${ }^{1}$ Mestre em Educação (UFPB/MPPGAV). E-mail: deboralopesjp@gmail.com

2 Doutor em Educação (USP). Professor e pesquisador da UFPB. E-mail: luizsjunior@gmail.com
} 
resources in the middle of the financial year 2014, without any study or planning, was the fundamental cause for the expressive return of such resources, confirming the hypothesis raised initially.

Keywords: Postgraduate studies; Management; Funding Policies; Planning; PROAP.

\section{Resumen}

El presente trabajo tiene por objetivo central analizar la gestión de los recursos del PROAP (Programa de Apoyo a la Post-Graduación) en el marco de la UFPB en el año 2014. Grandes desafíos y metas fueron establecidos para la Post-Graduación brasileña por el Plan Nacional de Post-Graduación - PNPG (20112020) y hay relativo consenso en cuanto a la necesidad de ampliar la inversión. Sin embargo, los recursos del PROAP encaminados a UFPB no se utilizaron en su totalidad en el año 2014. Se cuestiona, por lo tanto, la forma en que se realizó la gestión de esos recursos por las Unidades Gestoras responsables de la aplicación de los recursos. Aunque son considerados de pequeña escala en relación al presupuesto total de la UFPB, son imprescindibles para el pleno desarrollo del Post-Graduación. De ahí la relevancia de estudiar la gestión de tales recursos. Con base en datos obtenidos del Tesoro Gerencial, CAPES y UFPB, se constató que el cambio gerencial de los recursos PROAP en medio del ejercicio financiero de 2014, sin ningún estudio o planificación, resultó en la expresiva devolución de tales recursos.

Palabras Clave: Postgrado; Gestión; Políticas de Financiamiento; Planificación; PROAP.

Este artigo objetiva analisar a gestão dos recursos Programa de Apoio à PósGraduação (PROAP) na Universidade Federal da Paraíba (UFPB). Este programa, sob tutela da Coordenação de Aperfeiçoamento de Pessoa de Nível Superior (CAPES), tem por objetivo proporcionar melhores condições para formação de pesquisadores e o aprofundamento do conhecimento nos cursos de Pós-Graduação stricto sensu do Brasil.

O estudo, desenvolvido no âmbito de um mestrado profissional, buscou, inicialmente, situar as condições de financiamento do ensino superior e da pósgraduação no Brasil. Em seguida, verificou como a UFPB planejou o desenvolvimento de sua Pós-Graduação. Num terceiro momento, com base em dados primários e secundários, analisou a execução dos recursos PROAP na UFPB em 2014, ano em que a instituição deixou de utilizar parcela expressiva dos recursos destinados à pósgraduação.

As fontes principais da pesquisa foram o Tesouro Gerencial, uma ferramenta nova que possibilita a consulta da execução orçamentária e financeira do Governo Federal e de todos os seus órgãos; a CAPES, através de relatórios de gestão e; e a UFPB, por meio de relatórios fornecidos pela Pró-Reitoria de Administração. Foram feitas análises comparativas com outras Instituições Federais de Ensino Superior (IFES) da aplicação desses recursos.

\section{Financiamento do ensino superior no Brasil}

A legislação brasileira atribui à União, aos Estados, ao Distrito Federal e aos Municípios a responsabilidade pela administração do sistema educacional brasileiro. 
Assim sendo, consagrou-se a existência de três sistemas de ensino em regime de colaboração entre as referidas instâncias, tendo cada instância um sistema próprio de ensino.

A Constituição Federal de 1988, para assegurar os recursos públicos para a manutenção do ensino, garante que a União deverá aplicar não menos que 18\% de seus recursos, enquanto os Estados, o Distrito Federal e os Municípios devem aplicar um mínimo de $25 \%$ de suas receitas provenientes de impostos. 0 governo federal deve aplicar os recursos na administração do seu próprio sistema de ensino, em programas próprios, bem como em transferências para os sistemas estaduais e municipais, em razão da função redistributiva e supletiva, visando garantir igualdade de oportunidades educacionais e um padrão mínimo de qualidade de ensino.

No ano de 2014, o Brasil contava com 2.368 instituições de ensino superior, divididas entre Universidades, Centros Universitários, Faculdades, Institutos Federais e CEFET. A maior parte das Instituições de ensino superior no Brasil é privada, cerca de $87 \%$ do total, e respondiam por $75 \%$ do total de matrículas realizadas no ensino superior no Brasil em 2014. Já o sistema federal de ensino superior era composto por 63 universidades, 04 faculdades e 40 Institutos Federais e CEFET, totalizando um pouco mais do que 15\% de matrículas em 2014. As demais instituições estaduais e municipais foram responsáveis por cerca de 10\% do total de matrículas em 2014, presentes em 191 instituições em todo o Brasil.

A maior concentração de gastos do Governo Federal com a educação superior dáse através do Ministério da Educação. 0 gráfico abaixo mostra a evolução do orçamento do MEC dos anos de 2004 a 2014, com valores devidamente corrigidos para 2014 pelo IPCA. Nota-se que, em termos reais, o orçamento triplicou no período, passando de R\$ 29,5 bilhões em 2004 para R\$ 95,2 bilhões em 2014. 
Gráfico 1- Evolução do orçamento do MEC 2004 a 2014, com valores atualizados para 2014 pelo IPCA

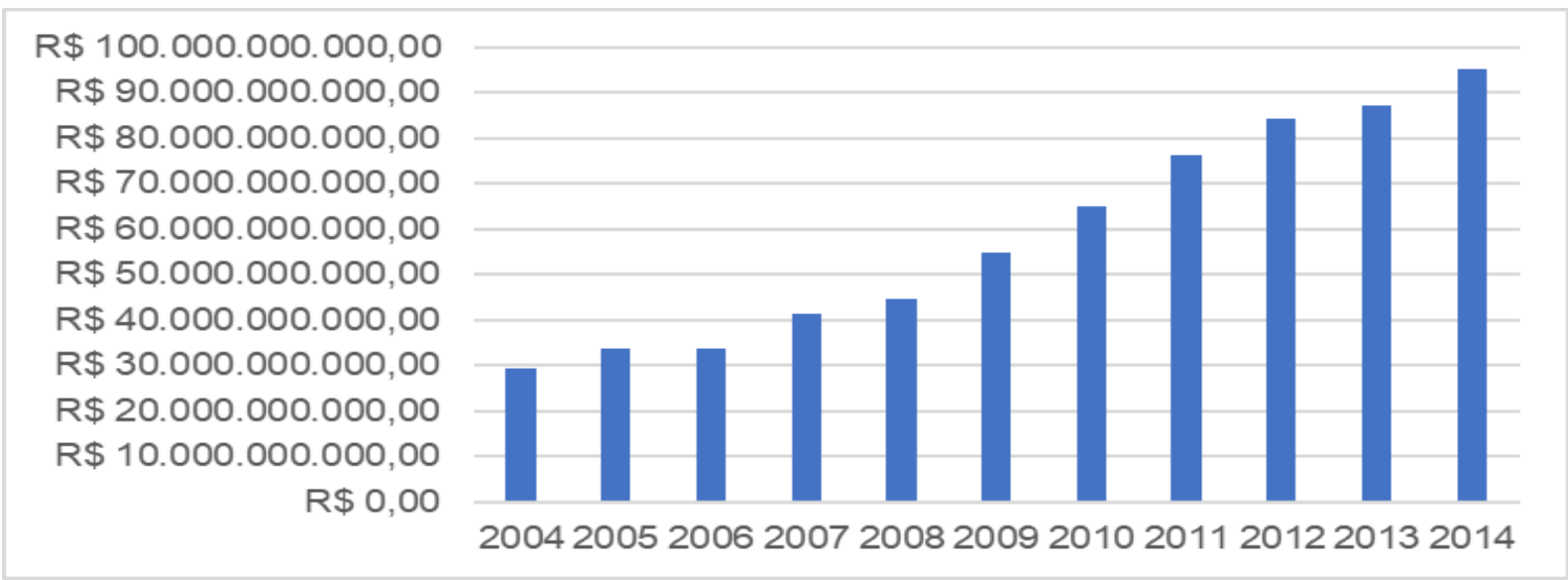

Fonte: Elaboração própria com base nos dados do SigaBrasil.

Detalhando as despesas do Governo Federal em educação, a tabela 4 apresenta os gastos com os tradicionais grupos de natureza de despesa. Verifica-se que de 2004 a 2014 houve um crescimento de mais de $1.000 \%$ nos investimentos e nas inversões financeiras, mas que, no entanto, representam apenas cerca de $24 \%$ da despesa total, enquanto que os gastos com pessoal, encargos sociais e outras despesas correntes equivalem a todo o restante, cerca de $76 \%$ do total.

Quadro 1- Despesa do Governo Federal em Educação por Grupo de Natureza da Despesa: 2004 a 2014.

\begin{tabular}{|l|c|c|c|c|c|}
\hline & \multicolumn{3}{|c|}{ R\$ Bilhões de 2014 } & \multicolumn{2}{c|}{ Participação \% no total } \\
\cline { 2 - 6 } & $\mathbf{2 0 0 4}$ & $\mathbf{2 0 1 4}$ & Var. \% & $\mathbf{2 0 0 4}$ & $\mathbf{2 0 1 4}$ \\
\hline $\begin{array}{l}\text { Pessoal e } \\
\text { encargos sociais }\end{array}$ & 11.890 & 29.723 & $150 \%$ & $49 \%$ & $32 \%$ \\
\hline $\begin{array}{l}\text { Outras despesas } \\
\text { correntes }\end{array}$ & 10.741 & 42.038 & $291 \%$ & $44 \%$ & $45 \%$ \\
\hline Investimento & 729 & 8.690 & $1.093 \%$ & $3 \%$ & $9 \%$ \\
\hline $\begin{array}{l}\text { Inversão } \\
\text { financeira }\end{array}$ & 1.094 & 13.750 & $1.157 \%$ & $4 \%$ & $15 \%$ \\
\hline Total & $\mathbf{2 4 . 4 5 3}$ & $\mathbf{9 4 . 2 0 1}$ & $\mathbf{2 8 5 \%}$ & $\mathbf{1 0 0 \%}$ & $\mathbf{1 0 0 \%}$ \\
\hline
\end{tabular}

Fonte: Elaboração própria com base no Sistema Siga Brasil e IBGE

Ressalte-se que o investimento público também está presente no ensino superior privado, que, como já visto anteriormente, perfaz cerca de $87 \%$ de Instituições de todo o sistema de ensino superior do Brasil. Tal investimento efetiva-se através da concessão 
de financiamento, com o Fundo de Financiamento Estudantil (FIES) e de bolsas de estudo integrais ou parciais com o Programa Universidade para Todos (PROUNI). No gasto com este nível de ensino, também estão incluídos o pagamento de bolsas de PósGraduação, a transferência de valores para entidades privadas, a exemplo do Sistema S, entre outros.

Verifica-se, portanto, que houve na política de investimentos na educação superior do Brasil, uma tendência de aumento de recursos no período analisado. Como consequência, a pós-graduação também se beneficiou do incremento dos gastos públicos.

\section{0 financiamento da Pós-Graduação: o papel da Coordenação de Aperfeiçoamento de Pessoal de Nível Superior - CAPES}

As Universidades Públicas e os Institutos de pesquisa são os maiores beneficiários dos recursos destinados à pesquisa científica, uma vez que são nessas instituições que se desenvolvem quase que a totalidade das atividades científicas e os cursos de Pós-Graduação stricto sensu do país.

Os recursos que constituem o sistema de financiamento da Pós-Graduação brasileira são provenientes do Tesouro Nacional; Agências de fomento nacionais e estaduais; Fundos setoriais de pesquisa; empresas públicas ou privadas; e de receitas próprias. Os recursos do Tesouro Nacional destinam-se, essencialmente, ao pagamento de pessoal e benefícios das Instituições Federais de Ensino Superior (IFES), proporcionando sua manutenção. Tais recursos não são suficientes para o fomento da Pós-Graduação das IFES, e, por isso, as atividades de pesquisa e Pós-Graduação são atendidas, em sua maioria, através de recursos provenientes das Agências de fomento.

No entanto, segundo o Plano Nacional de Pós-Graduação (PNPG) 2011-2020, não há uma metodologia consolidada a ser aplicada pelas entidades e órgãos financiadores da Pós-Graduação, o que dificulta a identificação de todas as fontes de financiamento possíveis para esse nível de ensino. Dessa forma, o financiamento da Pós-Graduação Brasileira será analisado em sua esfera federal, através de uma das maiores instituições de fomento, a CAPES, apesar de existir outras fontes de origem federal, estadual ou de setores produtivos não governamentais.

Além de políticas educacionais, o auxílio de recursos financeiros é essencial para a promoção da implantação, consolidação e expansão da Pós-Graduação stricto sensu no 
Brasil. Tais recursos, oriundos das agências de fomento, instituições financeiras ligadas ao Governo, são de extrema importância para a manutenção dos cursos de mestrados e doutorados do país, bem como de seus pesquisadores e pesquisas científicas, proporcionando apoio à capacitação de pessoal e ao desenvolvimento científico e tecnológico.

Ademais, o papel das agências de fomento vai muito além que a de um simples agente financiador. Seu papel expande-se em sua atuação na articulação e elaboração de iniciativas, além das financeiras, para desenvolver a pesquisa do país. Neste estudo será destacado o papel da Coordenação de Aperfeiçoamento de Pessoa de Nível Superior CAPES, ligada ao Ministério da educação, órgão responsável pela destinação dos recursos do PROAP aos programas de pós-graduação, em nível de mestrado e doutorado do Brasil.

A CAPES foi criada pelo Decreto no 29.741, de 11 de julho de 1951, tendo por objetivo "assegurar a existência de pessoal especializado em quantidade e qualidade suficientes para atender às necessidades dos empreendimentos públicos e privados que visam ao desenvolvimento do país" (BRASIL, Decreto 29.741/51).

O referido decreto instituiu uma comissão para a promoção da CAPES, que inicialmente era chamada de Campanha. E foi sob o comando do Professor Anísio Teixeira ${ }^{3}$, como secretário geral, que a CAPES foi formalmente implantada em 1961. Segundo Mendonça (2003), Anísio Teixeira foi de fundamental importância para tornar a CAPES um instrumento de promoção e expansão da Pós-Graduação e da pesquisa científica nas Universidades.

Vale ressaltar que o Brasil se encontrava num processo de estruturação com o desenvolvimento do modelo de industrialização e vivia sob uma política desenvolvimentista, o que exigia a formação de especialistas que pudessem suprir as necessidades que o crescimento econômico iria impor.

Já nos primeiros anos de funcionamento da CAPES, foi implantado o Programa Universitário no qual professores estrangeiros foram contratados com o intuito de interação e cooperação entre as Instituições. Em 1953, segundo a CAPES, foram concedidas 79 bolsas, sendo 02 para formação no país, 23 para aperfeiçoamento no país

\footnotetext{
${ }^{3}$ Anísio Spínola Teixeira foi um jurista, educador e escritor brasileiro. Importante personagem da história da educação no Brasil, difundindo os ideais da Escola Nova que priorizava o desenvolvimento intelectual e capacidade de julgamento em detrimento do processo de memorização. Exerceu vários cargos executivos na Bahia e no Rio de Janeiro, além de ter participado ativamente da fundação da Universidade do Distrito Federal.
} 
e 54 no exterior. Já no ano seguinte, esse número pulou para 155 bolsas, sendo a maioria das bolsas destinadas à formação no exterior, o que ressalta a ideia de intercâmbio entre as instituições para formação dos docentes do ensino superior.

Para Mendonça (2003), os primeiros anos de atuação da CAPES configuraram-se num projeto institucional de reconstrução da universidade brasileira que visava sua adequação às necessidades do país, passando a contribuir para a construção do saber científico brasileiro.

A partir de 1965, com a classificação de 27 cursos do nível de mestrado e 11 no nível de doutorado, a CAPES passou a exercer função de acompanhamento e avaliação dos Programas Stricto Sensu oficialmente instalados no Brasil, uma vez consolidados pelo Parecer Sucupira. Com isso, a CAPES passa a exercer mais atribuições e receber mais apoio financeiro para prosseguir com seu papel na nova política para a PósGraduação, auxiliando em sua expansão.

Nos anos de 1970, a estrutura da CAPES é modificada pelo Decreto nº 74.299/74 e passa a ser considerado como Órgão Central Superior, passando a gozar de autonomia administrativa e financeira. Outra mudança refere-se à transferência da sede da CAPES do Rio de Janeiro para Brasília. E, ainda em 1970, foram instituídos os Centros Regionais de Pós-Graduação.

Em 1981, a CAPES passou a ser responsável pela elaboração do Plano Nacional de Pós-Graduação, a partir de sua segunda edição, o PNPG de vigência de 1982 a 1985. Além disso, passou a ser reconhecida como Agência Executiva do Ministério da Educação e Cultura junto ao sistema nacional de Ciência e Tecnologia, cabendo-lhe a elaboração, avaliação, acompanhamento e coordenação das atividades do ensino superior (CAPES, 2010).

Até o início dos anos de 1990, a CAPES não sofreu mudanças, vivendo um período de estabilidade caracterizado pela continuidade administrativa. Tal período de calmaria acabaria em 1990, com a extinção da CAPES pelo então presidente Fernando Collor de Mello. Houve intensa mobilização da opinião acadêmica e científica brasileira, bem como do próprio Ministério da Educação que foi contrário à extinção do órgão. A CAPES foi recriada pela Lei no 8.028, de 12 de abril de 1990, cerca de um mês após sua extinção. Em 1992, a CAPES foi instituída como Fundação Pública, o que fez com que sofresse uma reestruturação que a fortaleceu como Instituição responsável pelo acompanhamento e avaliação dos cursos de Pós-Graduação stricto sensu do Brasil. 
Em 2007, a Lei de no 11.502, homologada pelo então Presidente Luiz Inácio Lula da Silva, criou a Nova CAPES que passou a coordenar o Sistema Nacional de PósGraduação, bem como passou a atuar por diversas linhas de ação, quais sejam: avaliação da Pós-Graduação stricto sensu; promoção da cooperação científica internacional; investimentos na formação de recursos de alto nível no país e exterior; acesso e divulgação da produção científica e indução e fomento da formação inicial e continuada de professores para a educação básica nos formatos presencial e a distância. Deve-se destacar o enfoque dado à formação dos professores da educação básica, uma vez que tal atribuição foi consolidada dois anos depois, através do Decreto no 6755 de 2009, que instituiu a Política Nacional de Formação de Profissionais do Magistério da Educação Básica.

Outra linha de ação bastante repercutida é a avaliação da Pós-Graduação stricto sensu, isso porque afeta diretamente o aporte financeiro aos programas. Esse sistema de avaliação, que data dos anos de 1970, tem por objetivo estabelecer um padrão de qualidade dos programas e identificar quais cursos atendem ao referido padrão, impulsionando, dessa forma, a evolução do Sistema Nacional de Pós-Graduação como um todo.

Dessa forma, a CAPES desempenha papel essencial para expansão e consolidação da Pós-Graduação stricto sensu brasileira, sendo o seu papel de coordenar e avaliar de grande valia para os resultados alcançados pelo Sistema Nacional de Pós-Graduação, uma vez que contava, em 2014, com cerca de 3.905 cursos de mestrado, doutorado e mestrado profissional, com 325.230 pós-graduandos (CAPES, 2015.)

Para promover a expansão e consolidação da Pós-Graduação, a CAPES conta com um conjunto estruturado de Programas de fomento à Pós-Graduação. Interessante analisar também que o número de programas e projetos fornecidos pela CAPES é proporcional à evolução do seu investimento em bolsas e fomento dos anos de 2002 a 2012, conforme gráfico a seguir: 
Gráfico 2 - Evolução do investimento da CAPES em bolsas e fomento de 2002 a 2012, com valores atualizados para 2012 pelo IPCA

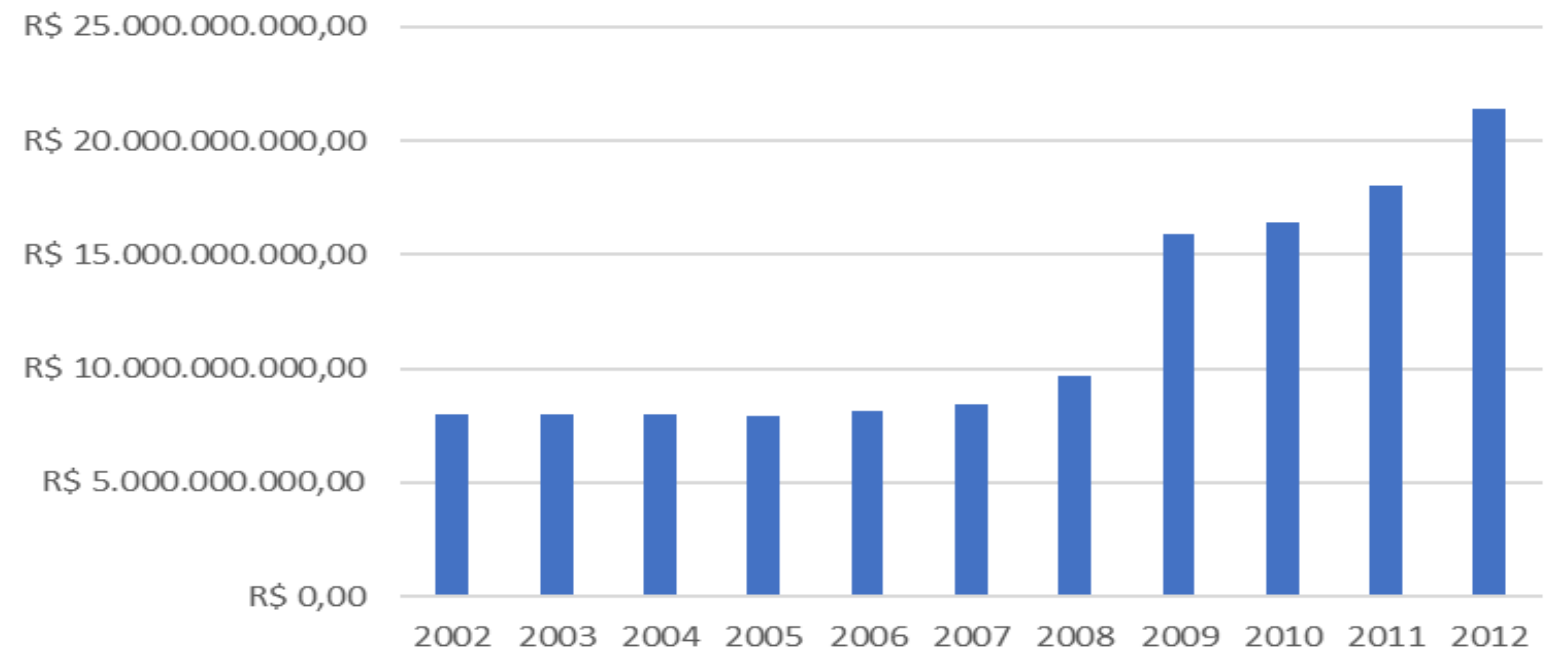

Fonte: Elaboração própria baseada nos dados do GeoCapes, 2014

Verifica-se que, de 2002 a 2008, há certa constância nos valores investidos pela CAPES em bolsa e fomento no país. A partir de 2009, percebe-se uma evolução do investimento, chegando, em 2012, a cerca de R 20 bilhões, mais que o dobro do valor investido em 2002, o que evidencia o incentivo desta agência e do governo federal na expansão e desenvolvimento da Pós-Graduação brasileira.

Só no ano de 2014, a CAPES forneceu um total de 105.791 bolsas nos seus mais diversos programas. Destaca-se que há uma grande concentração das bolsas concedidas pela CAPES para o mestrado, doutorado e a iniciação científica. Cerca de $45 \%$ das bolsas concedidas foram direcionadas para mestrados, enquanto que 37\% para o doutorado e 9\% para iniciação científica.

Dessa forma, a CAPES tem contribuído para a expansão, consolidação da PósGraduação Brasileira, preservando a qualidade dos cursos, através da avaliação e capacitando cada vez mais os pós-graduandos, docentes e pesquisadores, favorecendo não só os programas, mas também a sociedade brasileira.

\section{Os recursos do PROAP - Programa de Apoio à Pós-Graduação}

O Programa de Apoio a Pós-Graduação (PROAP) foi regulamentado pela Capes através da Portaria 53, de 26 de maio de 2000 e posteriormente alterada pelas Portarias 
10, de 27 de março de 2002; Portaria 64, de 24 de março de 2010 e, finalmente, pela Portaria 154, de 28 de novembro de 2014, atualmente em vigor.

Vale salientar que esse programa se destina aos cursos de Pós-Graduação mantidos por Instituições Públicas que tenham programa de Pós-Graduação stricto sensu recomendado pela CAPES e que possuam cota de bolsa do Programa de Demanda Social (DS). Além disso, a Instituição deve manter uma estrutura administrativa para o gerenciamento dos recursos PROAP, geralmente sob a competência da Pró-Reitoria de Pesquisa e Pós-Graduação (PRPPG) das Instituições.

Ainda no tópico de requisitos para ingresso da instituição no PROAP, destaca-se a garantia de uma infraestrutura de ensino e pesquisa para o funcionamento dos programas, a responsabilização pelo cumprimento das obrigações estipuladas pela CAPES, bem como prestar contas e apresentar relatórios da gestão dos recursos PROAP.

Ponto importante é a exigência, por parte da CAPES, de que o acompanhamento orçamentário e financeiro e a fiscalização do PROAP sejam realizados por meio da PRPG ou outro órgão equivalente de gestão da Pós-Graduação stricto sensu. A Portaria também especifica as atribuições da CAPES para com o PROAP, sendo de sua responsabilidade o estabelecimento das normas e diretrizes do Programa, definir e transferir os recursos orçamentários e financeiros destinados às instituições e aos programas.

Os recursos do PROAP podem ser destinados ao custeio de despesas de material de consumo; serviços de terceiros de pessoa jurídica e pessoa física; diárias; passagens e auxílio financeiro ao estudante e ao pesquisador, além de outros elementos de despesas que estejam em consonância com as atividades-fim da Pós-Graduação e detalhados no Plano de Trabalho ou previstos no orçamento com a devida aprovação da CAPES.

Quanto às atividades que podem ser custeadas pelo PROAP, destacam-se a manutenção de equipamentos; a manutenção e funcionamento de laboratórios; serviços e taxas de importação, dentre outros. Vale ressaltar que é vedado pela portaria o pagamento de valores referentes a pró-labore, consultoria, gratificação ou remuneração para ministrar cursos e aulas e participar de bancas examinadoras.

Os investimentos da CAPES através do PROAP tiveram um aumento significativo no período analisados, conforme gráfico abaixo. 
Gráfico 3 - Evolução da concessão de recursos PROAP (em milhões R\$) no período de 2004 a 2014, com valores atualizados para 2014, pelo IPCA.

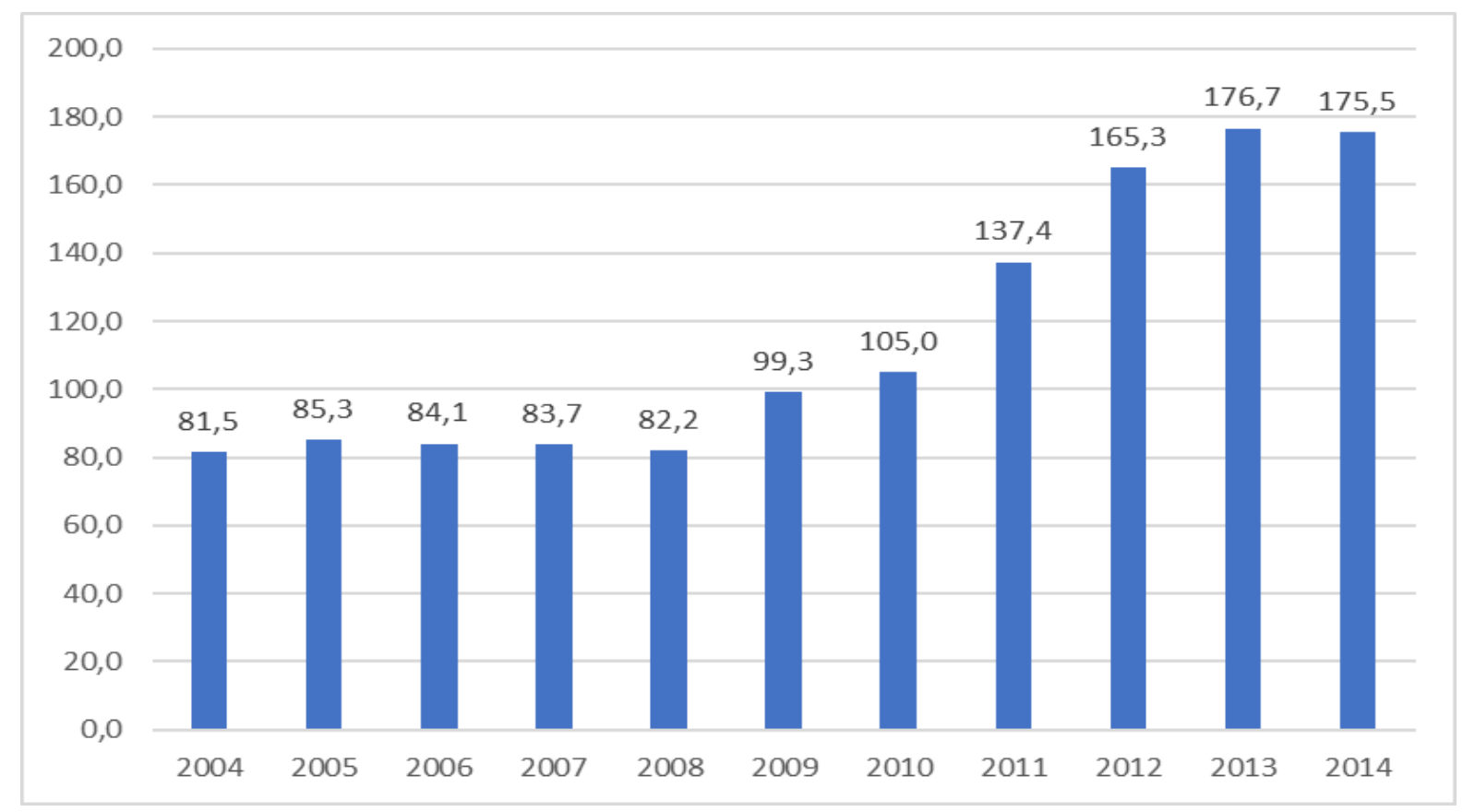

Fonte: Relatório de gestão da CAPES do exercício de 2014

Nota-se que não há variação significativa entre os anos de 2004 a 2008, sendo a partir de 2009 que se visualiza uma intensificação no aumento do volume de recursos destinados à Pós-Graduação brasileira, dobrando os valores de 2004. Naquele ano, cerca de 164 milhões de reais foram destinados aos programas de Pós-Graduação de todo o Brasil. Pode-se constatar que o PROAP abrange uma gama de despesas e atividades essenciais à manutenção e expansão dos programas de Pós-Graduação, o que evidencia sua importância, pois além da concessão de bolsas, os programas de Pós-Graduação necessitam de estrutura, material, intercâmbio de professores e tantos outros fatores.

Nesse sentido, torna-se fundamental analisar a gestão de tais recursos pelos programas de Pós-Graduação e este é o ponto central deste artigo: entender como se dá a gestão dos recursos PROAP pela UFPB, identificar possíveis problemas e apresentar soluções para que o PROAP atinja seus objetivos de proporcionar melhores condições para formação de pesquisadores e o aprofundamento do conhecimento nos cursos de Pós-Graduação stricto sensu do Brasil. 


\section{A gestão dos recursos da pós-graduação na UFPB}

A Universidade da Paraíba foi criada no ano de 1955 e federalizada em 1960, quando passou a ser denominada Universidade Federal da Paraíba, composta de estruturas universitárias existentes de João Pessoa e Campina Grande. Na década de 1980, a instituição contava sete campi em diversa cidades do Estado.

Em 2002, a UFPB foi desmembrada. A instituição conservou os campi de João Pessoa, Areia e Bananeiras. Em 2006, é criado o campus IV, no Litoral Norte do estado, abrangendo os municípios de Mamanguape e Rio Tinto.

Em 2007, a Universidade Federal da Paraíba apresentou seu plano de adesão ao Programa de Apoio a Planos de Reestruturação e Expansão das Universidades Federais (REUNI) ${ }^{4}$, que propôs uma série de medidas para retomar o crescimento do ensino superior público, criando condições para que as Universidades Federais promovam a expansão física, acadêmica e pedagógica. Com isso, a UFPB voltou-se para a reestruturação e ampliação de oferta de vagas e cursos de ensino, pesquisa e extensão. Destaca-se a criação de unidades avançadas em na região metropolitana de João Pessoa e a criação de novos Centros de ensino.

O perfil acadêmico e administrativo da UFPB demonstra bem a expansão da Instituição nos últimos anos, com crescimento expressivo tanto nos dados da graduação como nos da Pós-Graduação. 0 número de cursos presenciais na graduação saltou de 105, em 2009, para 130 em 2013. Com isso, as matrículas passaram de 25.559 para 32.827, no mesmo período. Os docentes foram de 1901 para 2831 entre 2009 e 2013, com uma titulação de $66,7 \%$ de doutores.

Dessa forma, alcançando um número maior de pessoas, gerando e difundido conhecimento, preparando-as para o mercado de trabalho, a UFPB tem por objetivo melhorar a qualidade de vida da população, desenvolver economicamente o Estado, integrando os Municípios e desenvolvendo sistemas produtivos, através da interação junto às empresas, objetivando ampliar a capacidade empreendedora e a potencialização das atividades produtivas do estado.

\footnotetext{
${ }^{4}$ O Programa de Apoio a Planos de Reestruturação e Expansão das Universidades Federais (REUNI) foi instituído pelo Decreto no 6.096 com o objetivo de "criar condições para a ampliação do acesso e permanência na educação superior, no nível de graduação, para o aumento da qualidade dos cursos e pelo melhor aproveitamento da estrutura física e de recursos humanos existentes nas universidades federais, respeitadas as características particulares de cada instituição e estimulada a diversidade do sistema de ensino superior". Cada Instituição, por decisão de seu Conselho Universitário, poderia aderir ao REUNI, sendo-lhes imposto o cumprimento de metas em contrapartida ao recebimento de recursos adicionais.
} 
A UFPB é umas das Instituições Federais de Ensino Superior de maior relevância do país. Em termos de orçamento anual, situa-se na 10ª posição entra as IFES, ocupando um lugar de destaque, em volume de recursos, no ensino superior brasileiro.

\section{Gestão dos recursos do PROAP na UFPB em 2014}

Tão expressiva quanto a UFPB, a sua Pós-Graduação também se destaca no cenário nacional, já que, mais uma vez, situa-se entre as 10 Instituições Federais de Ensino Superior que mais recebem recursos PROAP para o fomento e desenvolvimento de suas atividades, conforme apresentado na tabela a seguir:

Quadro 2 - Distribuição do PROAP por IFES em 2014

\begin{tabular}{|c|c|c|}
\hline Posição & Instituições Federais de Ensino Superior & Recursos PROAP \\
\hline $1^{0}$ & Universidade Federal do Rio Grande do Sul & $\mathrm{R} \$ 5.880 .526,00$ \\
\hline $2^{\circ}$ & Universidade Federal do Paraná & $\mathrm{R} \$ 5.435 .393,00$ \\
\hline 3 o & Universidade Federal de Santa Catarina & $\mathrm{R} \$ 5.327 .740,00$ \\
\hline 4 은 & Universidade Federal de Pernambuco & $\mathrm{R} \$ 5.018 .697,61$ \\
\hline 5은 & Universidade Federal do Rio de Janeiro & $\mathrm{R} \$ 4.847 .540,00$ \\
\hline 60 & Fundação Universidade de Brasília & $\mathrm{R} \$ 4.676 .906,66$ \\
\hline 7 음 & Universidade Federal da Bahia & $\mathrm{R} \$ 4.350 .866,00$ \\
\hline 80 & Universidade Federal da Paraíba & $\mathrm{R} \$ 4.296 .400,00$ \\
\hline 9o & Universidade Federal do Rio Grande do Norte & $\mathrm{R} \$ 4.153 .364,00$ \\
\hline $10^{\circ}$ & Universidade Federal do Ceará & $\mathrm{R} \$ 3.940 .147,00$ \\
\hline
\end{tabular}

Fonte: Elaboração própria com base nos dados do Relatório de gestão da CAPES de 2014.

Neste caso, a UFPB situa-se na 8ª posição entre todas as IFES do Brasil, sendo a $3^{\text {a }}$ na região Nordeste, atrás apenas da Universidade Federal de Pernambuco (UFPE) e da Universidade Federal da Bahia (UFBA).

Tal panorama ressalta a importância da UFPB e sua Pós-Graduação, acarretandolhe uma maior responsabilidade em utilizar os recursos que lhe são destinados, de maneira a garantir a qualidade e as melhorias necessárias para o oferecimento do ensino, da extensão e da pesquisa científica.

Por isso, torna-se imprescindível que a gestão do PROAP seja planejada e executada em sua totalidade, embora, dentro do orçamento geral da universidade, seus recursos sejam considerados de pequeno volume, mas intrinsicamente fundamentais para garantir que os objetivos de fomentar e desenvolver a Pós-Graduação sejam alcançados, através da realização de bancas de defesa de mestrado e doutorado, da oferta de cursos e disciplinas com professores de outras Instituições, compras de 
materiais essenciais, entre outros. Nessa perspectiva, após análise do relatório de gestão dos recursos do PROAP na UFPB no ano de 2014, verificou-se que cerca de 22,51\% dos valores recebidos não foram executados e utilizados pelos programas de Pós-Graduação, sendo devolvidos à União no fim do exercício.

Deve-se destacar que a análise dos valores devolvidos no fim do exercício financeiro se refere àqueles empenhados até o dia 31 de dezembro de cada ano, excetuando-se os valores inscritos em Restos a pagar ${ }^{5}$ e que serão, ou não, pagos ao longo do ano que se inicia. Tais valores também influenciam o resultado final da execução, e que merece um estudo mais detido, o que foge ao escopo deste trabalho.

Isto posto, o gráfico 12 apresenta, desde o início da vigência do PROAP, no ano de 2000, até o ano de 2015, o percentual dos valores devolvidos pela UFPB ao fim de cada exercício.

Gráfico 4 - Evolução dos recursos PROAP devolvidos pela UFPB ao final de cada exercício de 2000 a 2015

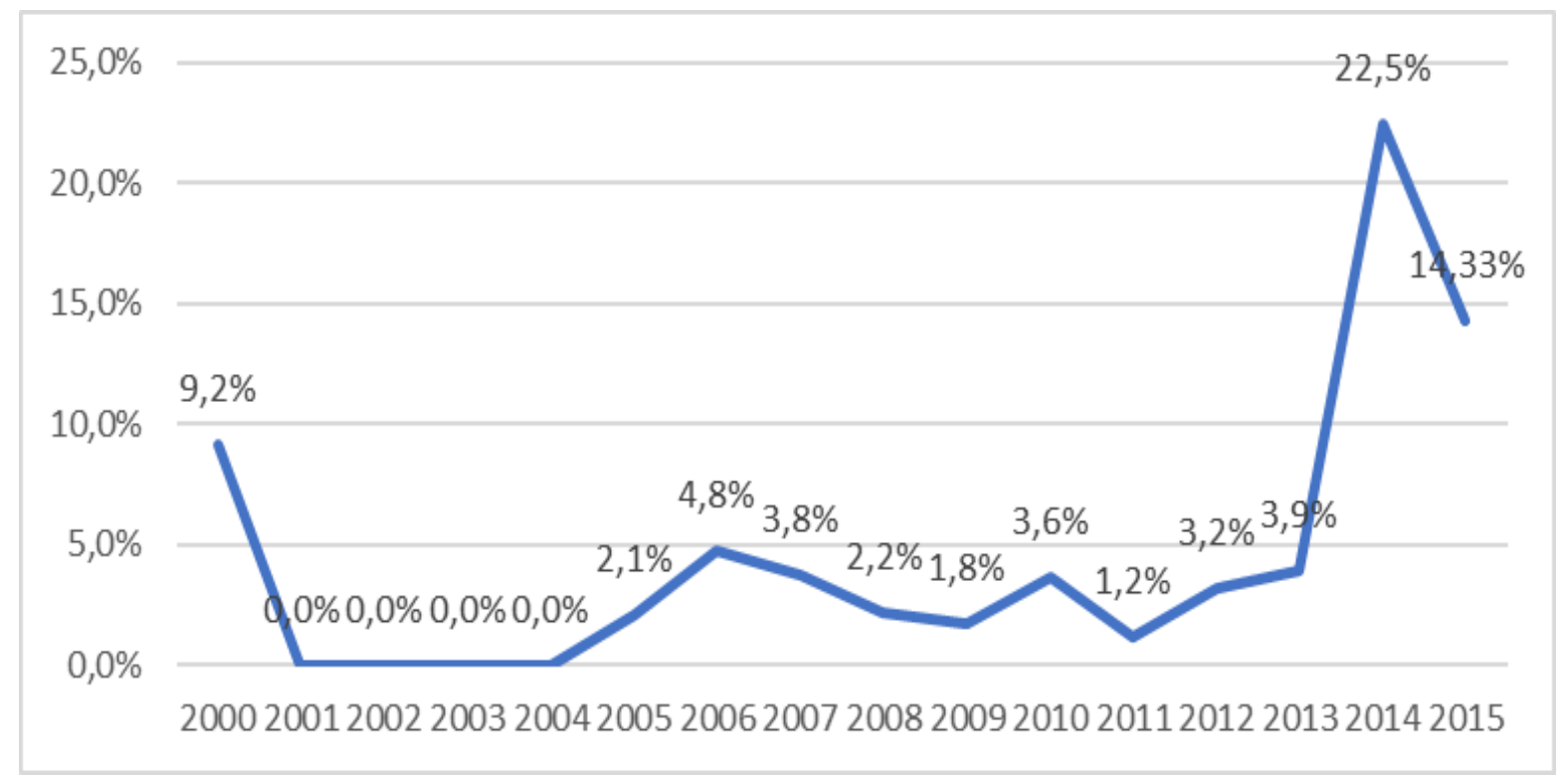

Fonte: Elaboração própria com base nos relatórios de controle de orçamento da UFPB

\footnotetext{
5 Segundo o Tesouro Nacional, define-se Restos a Pagar como sendo as despesas empenhadas, mas não pagas até o dia 31 de dezembro, distinguindo-se as processadas das não processadas. Processadas são as despesas inscritas em Restos a pagar, liquidadas e não pagas. Não Processadas, são as despesas empenhados e não liquidados.
} 
Nota-se que a porcentagem do valor devolvido em 2014 destoa completamente de todos os outros anos, o que demonstra que foi um ano atípico, sendo imprescindível sua análise mais aprofundada.

Portanto, questionam-se os motivos pelos quais, cerca de $\mathrm{R} \$ 967$ mil reais, de R\$ 4 milhões recebidos, foram devolvidos, enquanto que se defende e reconhece que a PósGraduação brasileira desenvolver-se-á com o aumento e a utilização massiva dos investimentos governamentais.

Além da UFPB, analisaram-se também os percentuais de recursos PROAP não executados em 2014 de outras IFES de mesmo porte na região Nordeste, conforme gráfico a seguir:

Gráfico 5 - Devolução dos recursos PROAP em 2014 pelas principais IFES do Nordeste

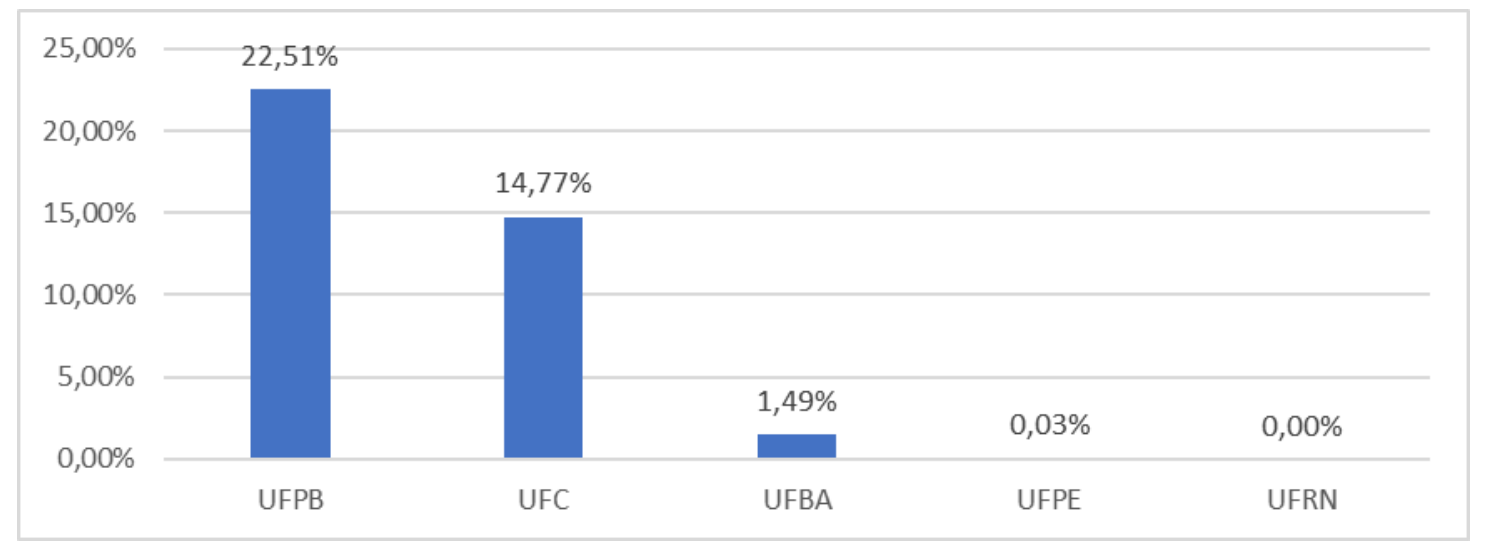

Fonte: Elaboração própria com base nos dados do Tesouro Gerencial.

Constata-se que a UFPB foi a IFES que mais devolveu recursos, seguida da Universidade do Ceará (UFC), com 14\%. Destaca-se a execução realizada pela Universidade Federal do Rio Grande do Norte (UFRN), com praticamente $100 \%$ de utilização dos recursos PROAP, bem como a UFPE e a UFBA que também obtiveram bons resultados na execução dos recursos.

Tal análise evidencia a existência de problemas, na gestão do PROAP na UFPB em 2014, que precisam ser identificados e solucionados para que os programas possam oferecer melhores condições para formação de recursos humanos e para produção de conhecimento. Para tanto, a gestão dos recursos PROAP em 2014 pela UFPB será analisada de forma aprofundada nos pontos a seguir. 


\section{Análise da execução dos recursos PROAP em 2014}

No ano de 2014, através do Termo de Cooperação 1384/2014, a CAPES repassou os recursos PROAP à UFPB, com o objetivo de custear e desenvolver as atividades dos seus programas de Pós-Graduação, visando proporcionar melhores condições para a formação de recursos humanos.

0 termo de cooperação, que previa o repasse de $R \$ 4.296 .400,93$, teve sua vigência iniciada em 11 de fevereiro de 2014, conforme relatório de gestão da CAPES daquele ano. Assim, através da nota de crédito de $n^{0} 00077$, tais recursos foram repassados para a UFPB na data de 12 de fevereiro de 2014.

A partir de 18 de fevereiro, os recursos foram descentralizados e encaminhados para as suas respectivas unidades gestoras através de notas de dotação. Portanto, a partir desta data, os recursos PROAP já poderiam ser executados pelos programas de Pós-Graduação da UFPB, havendo tempo hábil para o melhor planejamento e execução dos recursos até o término de vigência do termo de cooperação, no caso dezembro de 2014.

No entanto, conforme já mencionado anteriormente, no ano de 2014, a UFPB devolveu cerca de $22 \%$ dos recursos repassados pela CAPES, montante bastante expressivo e completamente destoante dos anos anteriores. Por isso o interesse de estudo na gestão e execução do PROAP na UFPB nesse período.

Um fato a se destacar, e que será analisado posteriormente, é que, a partir do mês de maio do ano de 2014, a execução dos recursos do PROAP passou a ser realizada pela PRA, uma vez que a PRPG deixou de ser uma unidade gestora, sob a explicação formal de que a equipe e estrutura da PRPG não seriam suficientes para suprir as necessidades dos programas.

Antes de uma análise mais aprofundada e individualizada da gestão dos programas escolhidos para a pesquisa, torna-se relevante analisar os dados gerais da UFPB, tais como os valores recebidos, remanejados, executados e devolvidos por cada natureza de despesa que o PROAP abrange em seu termo de cooperação. Assim, após identificação de cada natureza de despesa, há subsídios para a análise da tabela com a descrição da gestão dos recursos PROAP pela UFPB em 2014 que se segue: 
Quadro 3 - Execução dos créditos recebidos pela UFPB através do termo de cooperação PROAP 1384/2014.

\begin{tabular}{|c|c|c|c|c|c|}
\hline $\begin{array}{c}\text { Natureza } \\
\text { de despesa }\end{array}$ & $\begin{array}{c}\text { Valor total } \\
\text { recebido } \\
\text { conforme nota } \\
\text { de crédito da } \\
\text { CAPES (R\$) }\end{array}$ & $\begin{array}{c}\text { Valor total após } \\
\text { remanejamento } \\
\text { s solicitados } \\
\text { (R\$) }\end{array}$ & $\begin{array}{c}\text { Valor } \\
\text { executado } \\
\text { (R\$) }\end{array}$ & $\begin{array}{c}\text { Valor não } \\
\text { executado } \\
\text { (R\$) }\end{array}$ & $\begin{array}{c}\text { Percentual } \\
\text { dos } \\
\text { recursos } \\
\text { não } \\
\text { executados }\end{array}$ \\
\hline 339014 & $816.316,18$ & $745.297,52$ & $389.979,73$ & $355.317,79$ & $47 \%$ \\
\hline 339018 & $1.074 .100,23$ & $1.001 .720,87$ & $836.502,09$ & $165.218,78$ & $16 \%$ \\
\hline 339030 & $343.712,07$ & $550.509,40$ & $489.116,27$ & $61.393,13$ & $11 \%$ \\
\hline 339033 & $945.208,20$ & $854.824,88$ & $529.666,19$ & $325.158,69$ & $38 \%$ \\
\hline 339036 & $257.784,06$ & $119.975,48$ & $98.300,73$ & $21.674,75$ & $18 \%$ \\
\hline 339147 & $42.964,01$ & $37.163,34$ & $11.892,24$ & $25.271,10$ & $68 \%$ \\
\hline 339039 & $816.316,18$ & $986.909,44$ & $973.441,84$ & $13.467,60$ & $13 \%$ \\
\hline TOTAL & $4.296 .400,93$ & $4.296 .400,93$ & $3.328 .899,09$ & $967.501,84$ & \\
\hline
\end{tabular}

Fonte: Elaboração própria com base nos dados fornecidos pela UFPB.

Dos dados acima, depreende-se que as despesas com o PROAP tiveram uma baixa taxa de utilização, sendo devolvido, ao fim do exercício, cerca de 68\% do valor recebido. Destacam-se também as taxas expressivas de devolução das despesas com passagens e diárias, com 38\% e 47\%, respectivamente. Com cerca de 89\% de utilização dos recursos, as despesas com material de consumo apresentam o menor índice de devolução dos valores recebidos.

Após a análise da gestão dos recursos de maneira geral, do valor como um todo, passa-se a realizar um estudo mais aprofundado dos programas escolhidos.

A UFPB conta com 52 programas de Pós-Graduação que recebem recursos do PROAP, tendo quatro unidades gestoras responsáveis pela execução de tais recursos; a PRPG, que iniciou o ano de 2014 como unidade gestora, repassando a gestão dos programas sob sua responsabilidade para a PRA; o CCEN; o CCA e o CCHSA. Isto posto, tendo em vista que os programas gerenciados pela PRPG, e posteriormente pela PRA, cerca de 42 cursos, representam cerca de $62 \%$ do total dos recursos PROAP direcionados à UFPB, optou-se por analisar a gestão exercida pela PRPG/PRA em 2014.

Além disso, ao definir as taxas de devolução de recursos PROAP em 2014 de cada unidade gestora da UFPB, constatou-se que o montante devolvido pela PRPG/PRA foi bastante expressivo, uma vez que, dos $\mathrm{R} \$ 967.501,84$ não executados pela UFPB, cerca de $\mathrm{R} \$$ 801.203,24 foram devolvidos pelos cursos geridos pela PRPG/PRA, o que representa cerca de $82 \%$ do total de devolução. 
A taxa de devolução da unidade gestora PRPG/PRA destoa das outras unidades, sendo possível concluir que tal montante contribuiu para o aumento significativo da taxa geral de devolução da UFPB. Daí que surge a importância e a justificativa para a delimitação do assunto da presente dissertação à gestão exercida pela PRPG/PRA.

Gráfico 6 - Percentual de devolução de recursos por unidade gestora da UFPB em 2014.

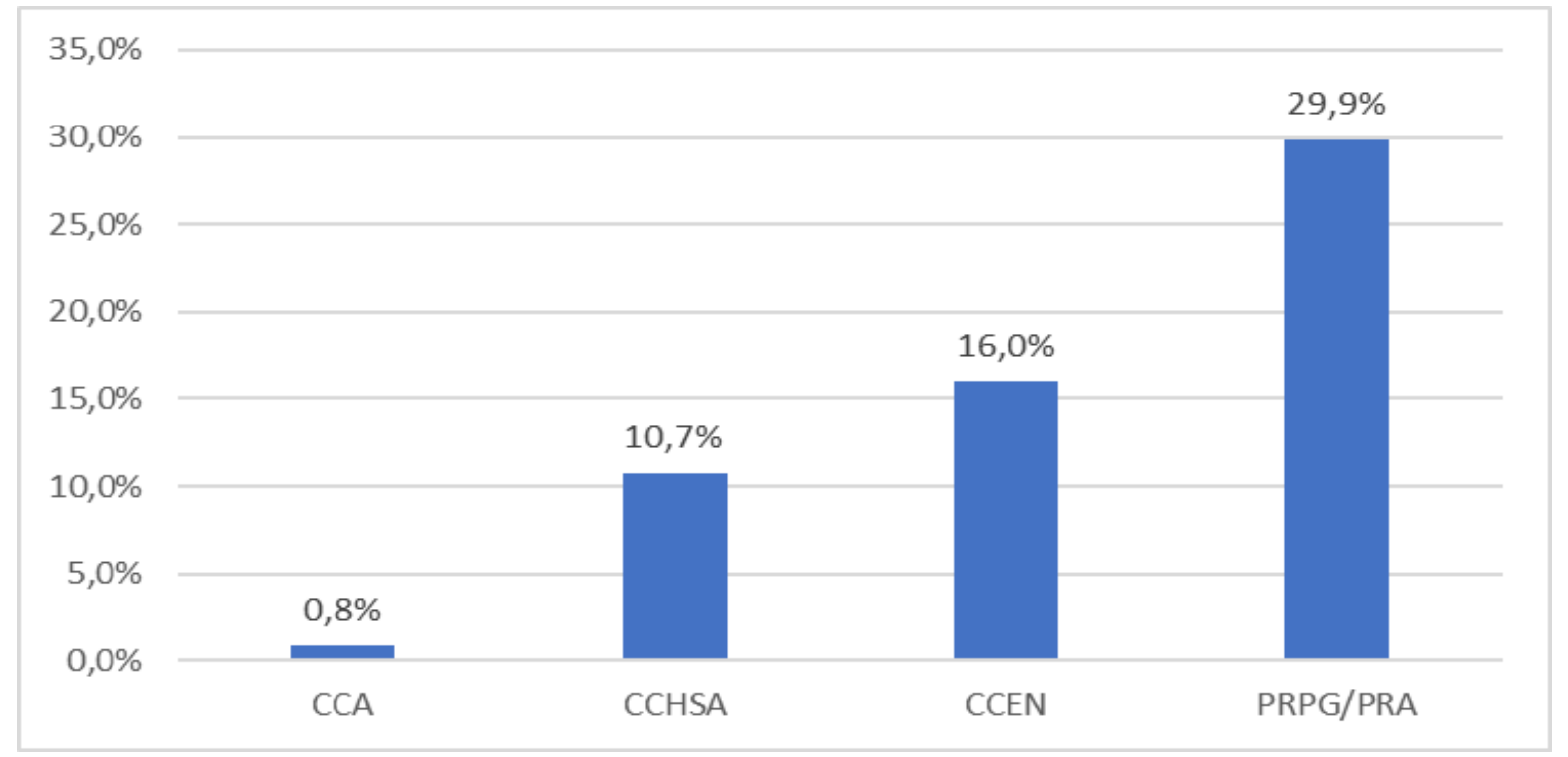

Fonte: Elaboração própria com base nos dados do Tesouro Gerencial.

Dessa forma, partindo para uma análise mais específica da unidade gestora PRPG/PRA, pesquisou-se junto aos referidos órgãos, dados da execução de cada programa por ele gerido. Identificou-se que todo o controle dos recursos PROAP é realizado por meio de planilhas de Excel, uma vez que os sistemas oficiais que controlam o orçamento e a execução dos recursos não fazem distinção entre os programas, direcionando os recursos para a unidade gestora a que os cursos são subordinados. Portanto, é através de tais planilhas que há a possibilidade de identificar a execução dos recursos por cada programa, em cada natureza de despesa.

Dos 42 cursos, apenas nove obtiveram uma taxa de devolução condizente com a média geral de anos anteriores da UFPB, abaixo de 5\%. Todos os outros 33 cursos apresentaram taxas bem superiores à média anterior. Dos programas que apresentaram maiores taxas de devolução, deve-se destacar o caso do programa de Biotecnologia, que foi criado no ano de 2014, o que, provavelmente, prejudicou a execução dos recursos recebidos pelo programa naquele ano. 
No mais, verifica-se que a taxa de devolução dos programas, salvo poucas exceções, é bastante expressiva e preocupante, o que demonstra que houve um desequilíbrio significativo na gestão dos recursos PROAP em 2014 que precisa ser analisado e identificado, com o intuito de proporcionar um melhor entendimento do ocorrido e o diagnóstico dos problemas, para que as soluções sejam apresentadas e implementadas.

Com isso, passa-se a analisar como se deu a gestão dos recursos PROAP no ano de 2014, a fim de identificar os fatores que motivaram uma devolução de recursos tão expressiva.

\section{Possíveis causas da devolução dos recursos}

Ao diagnosticar que houve um aumento expressivo da taxa de devolução dos recursos PROAP no ano de 2014, investiga-se, neste momento, quais seriam as causas ou fatos que contribuíram para este cenário. Assim, destaca-se como um dos fatores mais relevantes ocorridos naquele ano, a mudança de gestão dos recursos PROAP da PRPG para a PRA. Até o mês de abril de 2014, a PRPG exercia, de maneira exclusiva, a função de execução dos recursos PROAP dos 42 cursos centralizados do CAMPUS I.

Ocorre que, de forma surpreendente e inesperada, decidiu-se que a PRPG não mais seria a unidade gestora responsável pela execução de tais recursos, mas sim a PRA. Considera-se tal fato como surpreendente, pelo fato de que não havia qualquer conhecimento a respeito de uma mudança tão significativa, ou qualquer previsão nos documentos de planejamento da UFPB, a exemplo do PDI.

A partir do mês de maio de 2014, no meio do exercício financeiro, a execução dos recursos PROAP, geridos pela PRPG, passou a ser exercida pela PRA. Não houve a extinção da unidade gestora PRPG, mas sim, a transferência da gestão dos recursos PROAP para outro órgão auxiliar, isso porque a PRPG ainda apresenta pendências de execução de anos anteriores, o que impede seu cancelamento até a resolução dos pagamentos pendentes.

Dessa forma, a gestão dos recursos PROAP, de cerca de 42 cursos passou a ser realizada pela PRA. Uma das primeiras consequências sofridas por esta ação intempestiva foi o aumento considerável na demanda de trabalho da PRA, uma vez que, além de exercer as funções inerentes ao setor, incorporou os serviços de execução do PROAP. 
Destaca-se que, apesar da execução dos recursos ser de responsabilidade da PRA, ainda cabe à PRPG, a representação de órgão responsável pela Pós-Graduação da UFPB perante a CAPES, tanto que à PRA são disponibilizados apenas os dados necessários à execução, sem qualquer contato com o órgão de fomento.

Faz-se relevante destacar que não se consideram os procedimentos adotados pela PRA como ponto negativo. A exemplo disso, cita-se o caso das solicitações de passagens aéreas, que, na PRA, devem ser solicitadas com, no mínimo, 10 dias de antecedência, proporcionando ao setor tempo hábil para a solicitação, bem como, evitando a compra de passagens mais caras. Entende-se, portanto, que a normatização e a análise criteriosa dos processos são essenciais para a gestão dos recursos públicos, seja qual for sua fonte.

Ocorre que não houve uma ação conjunta de planejamento entre as pró-reitorias de Administração, de Pós-Graduação e de Planejamento (PROPLAN), com o intuito de planejar e coordenar as ações inerentes à execução dos recursos PROAP, o que, provavelmente, dificultou a criação e adaptação dos novos procedimentos.

\section{Considerações finais}

Ao se levantar todos os eventos que poderiam exercer alguma influência negativa na execução dos recursos PROAP em 2014 e analisá-los de maneira crítica, pode-se deduzir que a intempestiva e desorganizada mudança gerencial dos recursos PROAP para a PRA favoreceu a alta taxa de inexecução dos recursos, provocando consequências relevantes que podem ter afetado a qualidade e o desenvolvimento da Pós-Graduação da UFPB.

Com efeito, outros eventos que poderiam concorrer para tal acontecimento, como greves de servidores e contingenciamento de recursos, além de serem, até certo ponto rotineiros, não foram fatores impeditivos de uma boa execução orçamentária em outros anos. Uma vez comprovada que a taxa de devolução dos recursos PROAP da UFPB foi bastante significativa se comparada com outras universidades da mesma região, ou comparada à sua própria série histórica, e constatando-se que, entre as unidades gestoras, a taxa de devolução da PRPG/PRA se destaca, confirma-se que a falta de um planejamento adequado na mudança da gestão dos recurso do PROAP foi a principal causa para a devolução dos recursos pela UFPB. 


\section{Referências}

ARGUIN, G.O. O Planejamento Estratégico no Meio Universitário. Brasília, 1988.

BRASIL. Ministério da Ciência, Tecnologia, Inovação. Conselho Nacional Conselho Nacional de Desenvolvimento Científico e Tecnológico. Centro de Memória. Disponível em <http://centrodememoria.cnpq.br/Missao.html>. Acesso em: 13 jun. 2016.

. Coordenação de Aperfeiçoamento de Pessoal de Nível Superior. VI Plano Nacional de Pós-Graduação (PNPG)2011-2020. Brasília: CAPES, 2010.

. Coordenação de Aperfeiçoamento de Pessoal de Nível Superior. História e missão. Disponível em <http://www.CAPES.gov.br/sobre-a- CAPES/historia-emissao>. Acesso em: 13 jun. 2016.

Coordenação de Aperfeiçoamento de Pessoal de Nível Superior. Geocapes. Disponível em <http://geocapes.capes.gov.br/geocapes2/>. Acesso em: 03 jun. 2016.

. Coordenação de Aperfeiçoamento de Pessoal de Nível Superior. Relatório

de Gestão do exercício de 2014. Disponível em
http://www.capes.gov.br/images/stories/download/Contas_Publicas/2014_Relatorio_ de_Gestao_CAPES.pdf>. Acesso em: 19 out. 2016

Coordenação de Aperfeiçoamento de Pessoal de Nível Superior. Portarias. Disponível em http://www.capes.gov.br/component/content/article/53servicos/2340-portarias. Acesso em 19 out. 2016

Decreto no 29.741, 11 de julho de 1951. Institui uma Comissão para promover a Campanha Nacional de Aperfeiçoamento de Pessoal de Nível Superior. Brasília: 1951.

MENDONCA, A. W. P. C. A pós-graduação como estratégia de reconstrução da universidade brasileira. Educar em Revista. Curitiba, PR, Editora UFPR, n. 21, 2003. 

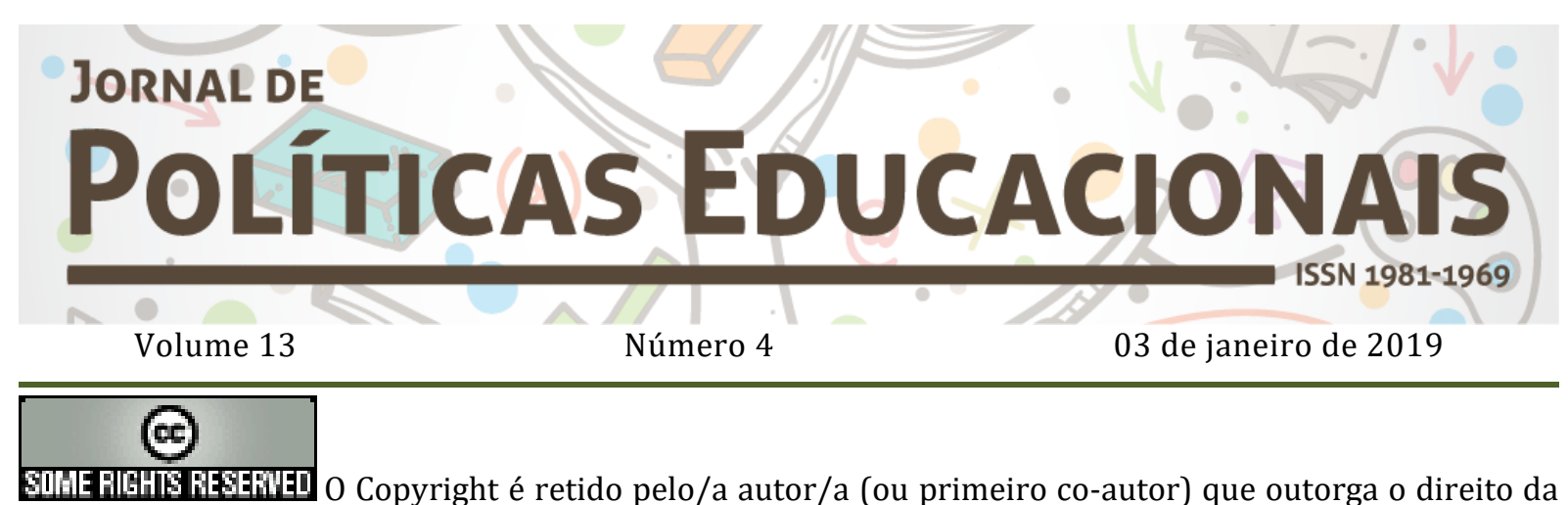

O Copyright é retido pelo/a autor/a (ou primeiro co-autor) que outorga o direito da primeira publicação ao Jornal de Políticas Educacionais. Mais informação da licença de CreativeCommons encontram-se em http://creativecommons.org/licenses/by-nc-nd/2.5. Qualquer outro uso deve ser aprovado em conjunto pelo/s autor/es e pelo periódico.

JoRnAl DE PolíticAs EduCACIONAIS é uma publicação do Núcleo de PolíticasEducacionaisdo Setor de Educação da Universidade Federal do Paraná - NuPE/UFPR, em consórcio com a Linha de Pesquisa em Políticas Educacionais do Programa de Pós-Graduação em Educação - PPGE/UFPR, que aceita colaboração, reservando-se o direito de publicar ou não o material espontaneamente enviado à redação. As colaborações devem ser enviadas ao NuPE/UFPR, conforme orientações contidas nas páginas do periódico na internet: http://revistas.ufpr.br/ipe.

\author{
Indexação: \\ BBE - Biblioteca Brasileira de Educação (MEC/INEP) \\ Clase (Base de Datos Bibliográfica de Revistas de Ciencias Sociales y Humanidades) \\ Diadorim - Diretório de Política de Acesso Aberto das Revistas Científicas Brasileiras (IBICT) \\ Google Scholar \\ Index Copernicus \\ Portal de Periódicos (CAPES) \\ SER - Sistema Eletrônico de Revistas da Universidade Federal do Paraná (SER/UFPR) \\ Sumários de Revistas Brasileiras (FUNPEC-RP) \\ DRJI - Directory of Research Journals Indexing
}

(Periódico integralmente disponível apenas em via eletrônica)

Jornal de Políticas Educacionais / Núcleo de Políticas Educacionais da Universidade Federal do Paraná -

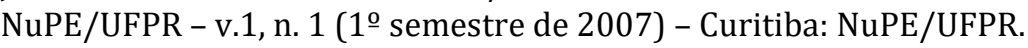

Volume 13, número 4 - Janeiro de 2019

ISSN 1981-1969

1. Educação - Periódicos. 2. Política Educacional - Periódicos. I. NuPE/UFPR

Comitê Editorial:

Elisângela Scaff (UFPR)

Ana Lorena Bruel (UFPR)

Gabriela Schneider (UFPR)

Conselho Editorial:

Andréa Barbosa Gouveia (UFPR), Ângela Hidalgo (UNICENTRO), Cesar GernominoTello (Universidad Nacional TresFebrero, Argentina),Gladys Beatriz Barreyro (USP), Juca Gil (UFRGS), Jefferson Mainardes 
(UEPG), João Ferreira de Oliveira (UFG), Luiz Souza Júnior (UFPB), Marcos Edgard Bassi (UFSC), Regina Maria Michelotto (UFPR), Robert Verhine (UFBA), Rosana Cruz (UFPI), Rubens Barbosa Camargo (USP), Sebastián Donoso Díaz (Universidad de Talca, Chile), Taís Moura Tavares (UFPR), TheresaAdrião (UNICAMP), Vera Peroni (UFRGS).

\author{
Jornal de Políticas Educacionais \\ Universidade Federal do Paraná \\ Setor de Educação \\ Núcleo de Políticas Educacionais - NuPE/UFPR \\ Rua Gal. Carneiro, 460 - 4o andar - Sala 407/C \\ 80.060-150 - Curitiba - PR - Brasil \\ Tel.: 41-3360-5380 \\ jpe@ufpr.br \\ http://revistas.ufpr.br/jpe
}

